\title{
Editor's Introduction: Combining Pragmatic Case Studies Within a Single Case Experimental Design
}

\author{
DANIEL B. FISHMAN ${ }^{\mathrm{a}, \mathrm{b}}$ \\ ${ }^{\text {a }}$ Graduate School of Applied and Professional Psychology, Rutgers University \\ b Correspondence regarding this article should be addressed to Daniel B. Fishman, Graduate School of Applied and \\ Professional Psychology, Rutgers University, 152 Frelinghuysen Road, Piscataway, NJ 08854 \\ Email:dfish96198@aol.com
}

\begin{abstract}
The target article in the current issue of PCSP by Fredrik Folke and associates (2012) documents and interprets six case studies of cognitive-behavioral therapy for Body Dysmorphic Disorder. This introduction places the article in a larger methodological context from my perspective as editor of the PCSP journal. I first review five types of case studies identified by McLeod (2010) in his seminal book on case study research. These include the main type of case study employed in PCSP, the Pragmatic Case Study, and four other kinds, including those that focus on theorybuilding, the adjudication of truth claims, the narrative experience of the participants, and singlecase experimental designs. I then discuss the advantages of combining Pragmatic Case Study designs with these other types. The Folke et al. article is an example of a successful such combination, integrating parallel pragmatic case studies within a single-case experimental design structure.
\end{abstract}

Key words: pragmatic case study; theory-building case study; adjudicated case study; narrative experience case; single case experimental design; case study; clinical case study; Body Dysmorphic Disorder; Exposure and Response Prevention (ERP)

\section{FIVE MODELS OF CASE STUDY RESEARCH}

As PCSP's Editor I'm taking the opportunity with this issue's target article by Folke et al. (2012) to highlight a relevant idea I've been developing over the past couple of years. The idea was first stimulated by John McLeod's (2010) seminal book on systematic and rigorous research using case studies in psychotherapy. From McLeod's extensive investigation of the psychotherapy case study literature, he has differentiated and categorized five distinct kinds of case study research. From my perspective, it seems a natural development to consider how different models might be combined to mutually enhance the knowledge produced by each. McLeod's categories are described below.

\section{The Pragmatic Case Study}

This model focuses on systematically documenting and interpreting exemplars of best clinical practice. As such, it strives in part to capture the clinical and narrative process of 
treatment from the perspective of the therapist. This is the model that I developed (Fishman, 1999) and which is embodied in this PCSP journal.

The approach to best practice incorporated in the Pragmatic Case Study model employs the late Donald Peterson's (1991) "Disciplined Inquiry" framework, outlined in Figure 1. As shown, the therapist begins with a focus on the Client and his or her presenting problems (component A). In this context, the therapist selects a general Guiding Conception (component B) with accompanying Clinical Experience and Research Support (component C). The therapist then conducts a comprehensive qualitative and quantitative Assessment (component D), including history, personality, living situation, symptoms and other problems, diagnosis, and strengths. Applying the Guiding Conception to the Assessment data then yields an individualized Formulation and Treatment Plan (component E). This plan is implemented during the Course of Therapy (component F). This clinical process is consistently subjected to a Therapy Monitoring (component G), generating feedback loops. If the therapy is not proceeding well, possible changes in the formulation and treatment plan might be required (component $\mathrm{H}$ ); and if the case is going well and meeting the needs of the client, arrangements for termination in consultation with the client might be made (component I). If the Therapy Monitoring results in showing that the client has been successful and/or the therapist and client agree that further therapy will not be productive, therapy is terminated and a Concluding Evaluation (component L) is conducted. This can yield feedback for either confirming — via assimilation - the original Guiding Conception (component $\mathrm{J}$ ), or revising that theory through accommodation (component $\mathrm{K}$ ). As shown in the multi-linear figure, a single set of linear, narrative headings can be derived; and it is these that form the generic structure of a Pragmatic Case Study.

\section{The Theory-Building Case Study}

This model provides a setting in which to develop and test theories of psychotherapy. It is exemplified in the work of William Stiles and associates, who have published some of their research in PCSP (Stiles, 2009; Gray \& Stiles, 2011; Schielke et al., 2011). Stiles et al. employ theory-building case studies to develop an "assimilation" theory of therapy, which views treatment progress as a function of the degree to which difficult, disturbing, and conflicting experiences are properly acknowledged, worked through, and connected to constructive action while being fully incorporated and integrated into the patient's internal experiencing. In Gray and Stiles' (2011) words, "A central tenet of theory-building case study research is that observations about rich material from individual cases — both the commonalities and differences — can be combined to inform and support theories about complex underlying psychological phenomena [like assimilation]" (p. 532).

\section{The Adjudicated Case Study}

This model looks systematically and intensively at evaluating the knowledge claims to be made about an individual therapy case-e.g., did positive change occur in the therapy, and if so, was it due to the therapy or other factors - using an adversarial truth-seeking system. This approach is distinctive in two ways (Fishman, 2011). First, detailed and intensive process and outcome data are collected from multiple perspectives, such as the client's qualitative point of view, the therapist's qualitative point of view, third party analysis of transcripts, and standardized 
Editor's Introduction: Combining Pragmatic Case Studies Within a Single Case Experimental Design

quantitative measures. Next, these data are subjected to a "quasi-judicial" analysis with (a) its systematic use of advocates (similar to prosecutors) and critics (similar to defense lawyers); (b) its use of the cross-examination of relevant actors and witnesses; and (c) its use of panels of jurors or judges, who come to a final decision on the truth of knowledge claims, taking into account the views of the advocates, critics, and witnesses. Two examples of this approach can be found in the work of Robert Elliott et al. (2009) and of Arthur Bohart (Bohart, Berry, Wicks, 2011; Bohart, Tallman, Byock, \& Mackrill, 2011).

\section{The Narrative Experience Case Study}

This model focuses on exploring the narrative experience and personal meaning of the therapy from both the client's and therapist's viewpoints. In McLeod's words, the aim is to " 'tell the story' of the experience of therapy, to convey what it was like to be a participant in therapy" (2010, p. 190). This approach is illustrated in the case studies of Ole Dreier (2008) and Thomas Mackrill (2008). One of Mackrill's cases, that of "Jane and Joe," is published in PCSP (Mackrill, 2011a, 2011b). In this case, Mackrill first had the client Jane and the therapist Joe independently write out diary entries after each treatment session of their experience in the session and its relationship to their concurrent life outside the therapy. Then, with some theoretical analysis, Mackrill integrated the two sets of diary material into a single whole, while retaining the narrative, personal, experiential level of detail in the original diaries.

\section{The Single Case Experimental Design Study}

This model views the case as a setting for single-case experiments in the tradition of the learning theory experiments of Pavlov and B.F. Skinner (Barlow, Nock, \& Hersen, 2009). This involves setting up distinctively different sequential conditions in a therapy intervention and quantitatively assessing during every session whether-and if so to what extent-each of those conditions has an effect on positive outcome over time.

An example provided by McLeod (2010) is Randall and Thyer's (1998) research involving six severely depressed women seen for 18 sessions of therapy. Three were provided individual cognitive therapy alone, which had been empirically supported for depression. On the hypothesis that lack of intimacy in close social relationships is an important contributor to depression, the other three clients received an initial two sessions of individual cognitive therapy, then alternative sessions of couple therapy consisting of "guided dialogue" training with their romantic partner, which included communication skills training and relationship repair. When six sessions of guided dialogue had been completed, individual cognitive therapy resumed to complete the 18 sessions. In line with the Skinner tradition in the experimental method, Randall and Thyer quantitatively measured each client's level of depression (on the Beck Depression Inventory) and social intimacy (on the Miller Social Intimacy Scale) during each therapy session, and they graphed their results on these two measures over the 18 sessions. Their findings on these two measures revealed that while all six patients recovered from depression, those who received the guided dialogue showed greater improvements in intimacy than did the three who received cognitive therapy alone. The experimental design that Randall and Thayer employed was thus able to demonstrate the differential quantitative impact of the six guided dialogue sessions compared with the six individual cognitive therapy sessions. This result illustrates the 
Editor's Introduction: Combining Pragmatic Case Studies Within a Single Case Experimental Design

goal of single case experimental designs: to quantitatively separate out the effects of different kinds of interventions.

\section{COMBINING MODELS}

As should be clear from the above, while all five case study models draw on the same qualitative and quantitative database that comprise a particular episode of psychotherapy, the models vary in the scope and kind of data they encompass and analyze. The most comprehensive is the Pragmatic Case Study, which has the broadest and most descriptive focus, including the various components of best practice and their interrelationships (see Figure 1). The other models are more selective in the data they analyze and have a less descriptive focus, including, respectively, data that are specifically relevant for theory-building, for the adjudication of particular truth claims about therapy, for documenting the narrative experience and personal meanings of clients and therapists, or for capturing the quantitative, sequential changes that occur in client symptoms as a function of different experimental conditions.

In fact, the case study content (although not necessarily the methods) of the other four models are included in the Pragmatic Case Study (PCS) model. Thus the PCS model includes theory (see component B, the Guiding Conception, in Figure 1); the adjudication-related search for particular conclusions about the nature and causes of therapy (see component $\mathrm{L}$, Conclusions); a description of the narrative experiences of the client and therapist (see component F, Course of Therapy); and quantitative data about the effects of different therapy conditions on outcome (see component G, Therapy Monitoring). What the other four models add is the opportunity to "zoom in" with more detail and conceptual elaboration on particular aspects of the case study, employing a different study design.

While each of the five case study models yields valuable types of knowledge in themselves, I propose that there are advantages to combining two or more of the models in the same case study, so that in general, the knowledge from different perspectives on the same case can enrich each other. The value of this type of enrichment by multiple perspectives has been argued both by social constructionists (e.g., Fishman, 1999; Gergen, 1991) and by mixed methods advocates (e.g., Teddlie \& Tashakorrie, 2009). As editor of the PCSP journal, I have therefore encouraged such combined designs. Particularly, in light of the point above that the Pragmatic Case Study contains the basic content of the other four models, I have encouraged case study authors to choose a Pragmatic Case Study design as a broader, more descriptive foundation upon which the more selective perspective of an alternative case study model can then be elaborated.

One example of such a "combined method" case study is that of "Cynthia" by Jefferson Singer and Laura Bonalume (2010). Here we find a Pragmatic Case Study integrated with a Theory-Building Case Study design. First the authors present a Pragmatic Case Study of therapy with "Cynthia," a 19-year old with anxiety and panic attacks oscillating with "acting out" behaviors (promiscuity, dangerous friendships, risk of life). In assessing Cynthia, the authors employed a coding system for "Autobiographical Memory Narratives" (AMNs) to explore ways in which Cynthia's memory narratives reflected a picture of her personality dynamics, cognitive complexity, primary defenses, and affective regulatory strategies. After setting out the Pragmatic 
Editor's Introduction: Combining Pragmatic Case Studies Within a Single Case Experimental Design

Case Study of Cynthia, Singer and Bonalume did a more intensive Theory-Building Case Study of Cynthia's case to further develop the theory of AMNs.

A second example is the case study of "Anna," by Ronald Miller (2011) and his colleagues that combines a Pragmatic Case Study and an Adjudicated Case Study. First Miller's graduate student Stacy Podetz (2011) presented a Pragmatic Case Study of the psychodynamic treatment of "Anna," an 18 year-old young woman who had a six-year history of self-injury, panic attacks, anxiety, disordered eating, and depression. Next Miller and his associates (Miller et al., 2011) subjected the case to an adjudication process. This involved a five-member panel consisting of senior practitioners and academics who conducted a five-hour hearing on the treatment of Anna, with the evidence consisting of Podetz's pragmatic case study and interpretations of the case by one person placed in a critic role and one, in an advocate role. The judges evaluated five knowledge claims about the severity of psychopathology; relationship of the symptom to defenses; therapeutic orientation; outcome; and role of counter-transference in the case.

In both the Singer and Bonalume and the Miller et al. examples, the Pragmatic Case Study provided a foundation so that the reader could obtain a systematic picture of the therapy case. Then the additional analysis utilizing a theory-building or an adjudicative model, respectively, was added "on top" of the Pragmatic Case Study, yielding a multi-layered approach that included both the more theoretical knowledge of the added layer and the more systematic and descriptive layer of the pragmatic case study "base." Since the Pragmatic Case Study contains the multiple elements of the holistically full case study, and since the theory-building or adjudicative models elaborate on particular parts of the full case study, combining them brings two important advantages: on one hand, (a) the theory-building or adjudicative focus of the more specialized case study enriches the "basics" of the Pragmatic Case Study; while (b) the holistic nature of the Pragmatic Case Study helps to connect the narrower results of the theory-building or adjudicative studies to the broader picture of the overall case. As a further aspect of this second point, since the Pragmatic Case Study is designed in part to capture the perspective of the therapist, the Pragmatic Case Study provides a link for the practitioner to better understand the theory-building or adjudicative components of the case study.

\section{THE FOLKE ET AL. COMBINATION}

The present issue of PCSP illustrates a third example of combining a Pragmatic Case Study and another case study design in the target article by Folke, Von Bahr, Assadi-Talaremi, and Ramnerö(2012). Specifically, Folke et al. employ a Single Case Experimental Design to structure the treatment of six clients with Body Dysmorphic Disorder (BDD). In line with such an experimental design, illustrated in the Randall and Thayer experimental design article described above, Folke et al. organized their treatment into distinct sequential phases and continuously measured BDD-related symptoms each day throughout the treatment. There were four consecutive therapy phases, which included: $\left(\mathrm{A}_{1}\right)$ Self-Monitoring [4 weeks]; $(\mathrm{B})$ Therapist Contact Together With Self-Monitoring (6 twice-a-week sessions); (C) Exposure and Response Prevention (ERP [also called "exposure therapy"], 14 twice-a-week sessions); and ( $\left.\mathrm{A}_{2}\right)$ Renewed Self-Monitoring (3 weeks). Besides the daily quantitative monitoring of BDD-related symptoms, the clients were quantitatively assessed at baseline and after each phase with standardized quantitative measures of BDD, depression, and global functioning. 
In addition to the experimental design, in Folke et al.'s study, each of the six clients is qualitatively described as he or she goes through the four phases, presenting in effect six parallel Pragmatic Case Studies. There is a common narrative structure for each case, including sections on: (a) Presenting Problem; (b) History; (c) Assessment of Thoughts, Feelings, and Behaviors as Related to the Client's BDD; (d) Individualized Case Formulation; (e) Individualized Treatment Plan for ERP; (f) Course of Treatment; and (g) Response to Therapy. While these narrative descriptions comprise Pragmatic Case Studies, at the same time the experimental structure in each case allows for an analysis of the contribution of the different phases to outcome, with a focus on the particular contribution made by the ERP treatment.

It is important to note, as pointed out by Folke and his colleagues, that the nature of the naturalistic clinical setting in which their study took place required them to limit the experimental power of the research design they used. For example, the length of the ERP phase was longer than the other phases, and thus its effects compared to the other phases could have been due to its longer time. Also, the phases were not controlled for sequence, and thus the fact that the ERP phase followed the Therapist Contact phase could have positively advantaged the ERP phase.

However, even when keeping the above limitations in mind, Folke et al.'s combined quantitative and qualitative results are very informative. In terms of the experimental design focus, Folke et al. found three distinct patterns in response to the therapy: three of the clients (Ms. A, Ms. B, and Ms. C) showed significant improvement in the BDD that could be isolated as occurring within the ERP phase; one client (Mr. D) significantly profited from the therapy as a whole but not from the ERP phase per se; and two of the clients (Ms. E and Ms. F) did not profit from the therapy.

For example, at the beginning of therapy Ms. A , a 24-year-old university student living alone, had concurrent diagnoses of social phobia and major depression associated with her BDDrelated preoccupation with her appearance. Ms. A. continued to have high BDD-related symptoms during the first two phases of the treatment. When she came to ERP Phase, Ms. A

expressed reluctance regarding the ERP method, but the therapist persisted and helped the client by grading exposure exercises even more than originally planned and by providing encouragement for every small step she agreed to take in the direction of exposure. During session two of the ERP phase, she walked around in the clinic hallways without make-up on. She was still worried about future exposures. However, as she acquired more experience, she learned she could master exposure exercises on her own. She exposed herself to numerous social situations without make-up on (e.g., sitting on the bus and walking in a mall while asking people questions). Eventually she confronted the highest ranked fear in her anxiety hierarchy: eating at a public restaurant without make-up. Ms. A repeated the exposures from the sessions as homework and had continued to do so at follow-up. At the end of treatment, Ms. A was without make-up for several days but planned to introduce it again at a restricted level. (2012, p. 263).

Mr. D, a 20-year-old high school student living at home, also had concurrent diagnoses of social phobia and major depression associated with his BDD-related preoccupation with his 
Editor's Introduction: Combining Pragmatic Case Studies Within a Single Case Experimental Design

appearance. However, while Mr. D had a similar experience to Ms. A up through the middle of the ERP phase, during this phase

Mr. D experienced a major setback when he became ill with an infection that affected his skin. As a result his obsessions became more intense. This changed the situation significantly for the client, not least of which was the expected adversity of the remaining feared events targeted in therapy. Together, Mr. D and his therapist chose to start over from the beginning of his fear and avoidance hierarchy. Mr. D did continue with ERP exercises on his own during phase $A_{2}$, and [only then] reported significant progress when he came in for the follow-up assessment. (2010, p. 270).

As a final example, Ms. E, a 35-year-old old woman living with a partner, had concurrent depression with her BDD concerns and had associated severe social limitations centering around her facial skin, facial hair, and hair. She continued to have high levels of BDD symptoms through the first two phases of therapy.

When starting Phase C, Ms. E initially confronted her fear of hair loss. She ruffled her hair, something she reported not having done in years. As she experienced that exposure worked for her, she agreed not to camouflage the skin area of focus. She reported feeling less preoccupied by this fear after having gone to work without make-up for a few days. Spring arrived some sessions into the ERP phase, and the increased exposure to sunlight made her very anxious about damaging her skin. This concern grew more intense as the temperature rose. Eventually, she developed panic attacks and started to avoid leaving home without sun protection. Due to increased rumination and depression, she had trouble concentrating during work and therapy sessions. Ms. E then became too afraid of the possible consequences of sun exposure to continue therapy, and as she began to report increased depression and suicidal ideation, she was offered and accepted medical treatment. ERP was discontinued and she received supportive therapy during evaluation of the medical intervention. (2010, p. 272). .

In sum, the experimental design in Folke et al.'s study helps to highlight the kind of effective role that ERP can play in treatment. At the same time the details presented in the Pragmatic Case Studies highlight the dynamics of individual variation in reaction to ERP, enhancing our understanding of those client and situational factors that distinguish successful and unsuccessful clients.

\section{MULLER AND SCHULTZ COMMENT ON FOLKE ET AL.}

Folke et al.'s article is followed with a commentary by Katherine Muller and Luke Schultz (2012), who focus on the process of exposure therapy. They point out that frequently therapist hesitancy to fully proceed with exposure therapy causes clients to resist it. Muller and Schultz combine their extensive clinical experiences with the scientific literature to derive strategies for how therapists can successfully persuade ("sell") clients to engage in exposure treatment. Since the scientific literature provides extensive evidence of the efficacy of exposure therapy when it is fully experienced by clients, this "selling job" is very important. Moreover, Muller and Schultz's strategies can help therapists to tailor their exposure therapy approaches to different clients, taking into account the kinds of different individual reactions to exposure therapy that Folke et al. document. 


\section{REFERENCES}

Barlow, D.H., \& Nock, M.K. (2008). Single case experimental designs: Strategies for studying behavior change (3rd Edition). Boston: Allyn \& Bacon.

Bohart, A.C., Berry, M., \& Wicks, C. (2011). Developing a systematic framework for utilizing discrete types of qualitative data as therapy research evidence. Pragmatic Case Studies in Psychotherapy, 7(1), Article 9, 145-155. Available: http://hdl.rutgers.edu/1782.1/pcsp_journal

Bohart, A.C., Tallman, K.L., Byock, G. \& Mackrill, T. (2011). The “Research Jury” Method: The application of the jury trial model to evaluating the validity of descriptive and causal statements about psychotherapy process and outcome. Pragmatic Case Studies in Psychotherapy, 7(1), Article 8, 101-144. Available: http://hdl.rutgers.edu/1782.1/pcsp_journal

Dattilio, F.M., Edwards, D.J.A., \& Fishman, D.B. (2010). Case studies within a mixed methods paradigm: Toward a resolution of the alienation between researcher and practitioner in psychotherapy research. Psychotherapy Theory, Research, Practice, Training, 47, 427441.

Dreier, O. (2007) Psychotherapy and everyday life. London: Cambridge University Press.

Elliott, R., Partyka, R., Alperin, R., Dobrenski, R., Wagner, J., Messer, S., Watson, J.C., \&n Castonguay, L.J. (2009). An adjudicated hermeneutic single-case efficacy design study of experiential therapy for panic/phobia. Psychotherapy Research, 19, 543-557.

Fishman, D.B. (1999). The case for pragmatic psychology. New York: NYU Press.

Fishman, D.B. (2011). A Promising strategy for critically evaluating case studies: Introduction to an issue on the adjudicated case study method. Pragmatic Case Studies in Psychotherapy, 7(1), Article 1,1-5. Available: http://hdl.rutgers.edu/1782.1/pcsp_journal

Folke, F., Von Bahr,M., Assadi-Talaremi, V., \& and Ramnerö, R. (2012). Exposure and response prevention in the treatment of body dysmorphic disorder-A case series.

Pragmatic Case Studies in Psychotherapy, 8(4), Article 2, 255-287. Available: http://hdl.rutgers.edu/1782.1/pcsp_journal

Gergen, K.R. (1991). The saturated self. Dilemmas of identity in contemporary life. New York: basic Books.

Gray, M.A., \& Stiles, W.B. (2011). Employing a case study in building an assimilation theory account of generalized anxiety disorder and its treatment with cognitive-behavioral therapy. Pragmatic Case Studies in Psychotherapy, Vol. 7(4), Article 5, 529-557. Available: http://hdl.rutgers.edu/1782.1/pcsp_journal

Mackrill, T. (2008) The Therapy Journal Project: A cross-contextual qualitative diary study of psychotherapy with adult children of alcoholics. PhD Dissertation. Copenhagen: Institute for Psychology, Copenhagen University.

Mackrill, T. (2011a). A diary-based, cross-contextual case study methodology: Background for the case of "Jane and Joe.” Pragmatic Case Studies in Psychotherapy, 7(1), Article 10, 156-186. Available: http://hdl.rutgers.edu/1782.1/pcsp_journal

Mackrill, T. (2011b). The case of "Jane and Joe": A diary-based, cross-contextual case study. Pragmatic Case Studies in Psychotherapy, 7(1), Article 11, 187-229. Available: http://hdl.rutgers.edu/1782.1/pcsp_journal 
McLeod, J. (2010). Case study research in counselling and psychotherapy. Thousand Oaks, CA: Sage.

Miller, R.B. (2011). Real Clinical Trials $\left(\mathrm{RCT}^{1}\right)$ : Panels of Psychological Inquiry for transforming anecdotal data into clinical facts and validated judgments: Introduction to a pilot test with the case of “Anna.” Pragmatic Case Studies in Psychotherapy, 7(1), Article 2, 6-36. Available: http://hdl.rutgers.edu/1782.1/pcsp_journal

Miller, R.B., Kessler, M.; Bauer, M.; Howell, S., Kreiling, K., \& Miller, M. (2011). Findings of the Panel of Psychological Inquiry convened at Saint Michael’s College, May 13, 2008: The case of “Anna” subjected to proof. Pragmatic Case Studies in Psychotherapy, 7(1), Article 7, pp. 95-100. Available: http://hdl.rutgers.edu/1782.1/pcsp_journal

Muller, K.L., \& Schultz, L.T. (2012). "Selling” exposure therapy. Pragmatic Case Studies in Psychotherapy, 8(4), Article 3, pp. 288-295. Available: http://hdl.rutgers.edu/1782.1/pcsp_journal

Peterson, D.R. (1991). Connection and disconnection of research and practice in the education of professional psychologists. American Psychologist, 46, 422-429.

Podetz, S. (2011). Seeing beyond the scars: A testament to “Anna.” Pragmatic Case Studies in Psychotherapy, 7(1), Article 3, 37-63. Available: http://hdl.rutgers.edu/1782.1/pcsp_journal

Randall, E.J, \& Thyer, B.A. (1998). Combining guided dialog with cognitive therapy for depressed women: Six single-case studies. Journal of Cognitive Psychotherapy: An International Quarterly, 12, 331-342.

Schielke, H.J., Stiles, W.B., Cueller, R.E., Fishman, J.L., Hoener, C., Del Castillo, D., Dye, A.K., Zerubavel, N., Walker, D.P., \& Greenberg, L.S. (2011). A case study investigating whether the process of resolving Interpersonal problems in couple therapy is isomorphic to the process of resolving problems in individual therapy. Pragmatic Case Studies in Psychotherapy, 7(4), Article 4, 477-528. Available: http://hdl.rutgers.edu/1782.1/pcsp_journal

Singer, J.A., \& Bonalume, L. (2010). Autobiographical memory narratives in psychotherapy: A coding system applied to the case of Cynthia. Pragmatic Case Studies in Psychotherapy, 6(3), Article 1, pp. 134-188. Available: http://hdl.rutgers.edu/1782.1/pcsp_journal

Stiles, W.B. (2009). Logical operations in theory-building case studies. Pragmatic Case Studies in Psychotherapy, 5(3), Article 2, 9-22. Available: http://hdl.rutgers.edu/1782.1/pcsp_journal

Teddlie, C. B., \& Tashakorrie, A. (2009). Foundations of mixed methods research: Integrating quantitative and qualitative approaches in the social and behavioral sciences. Thousand Oaks, CA: Sage. 
Figure 1. Therapy as “Disciplined Inquiry” (adapted from D.R. Peterson, 1991)

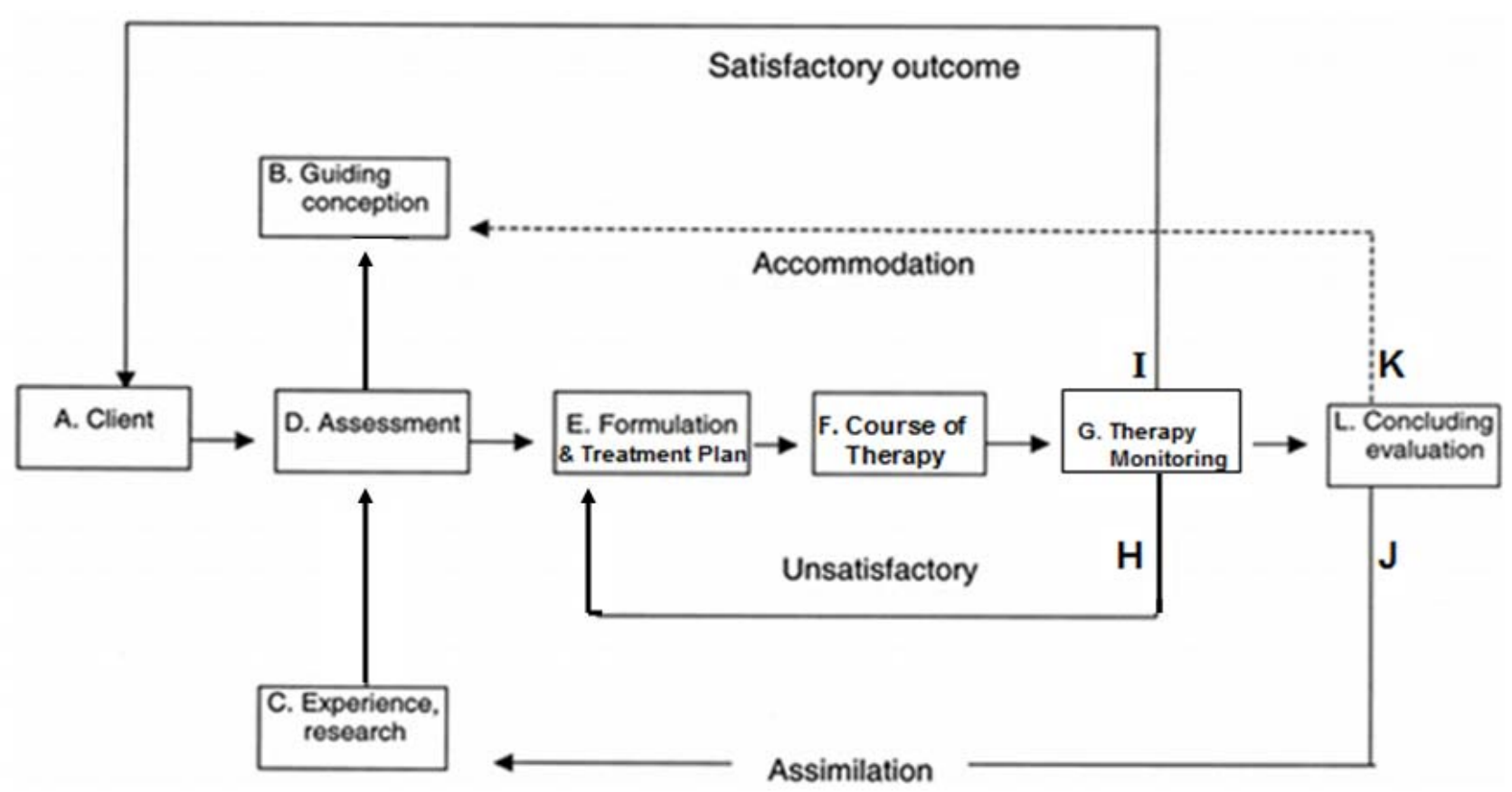

\section{Common Headings in a Pragmatic Case Study}

1. Case Context and Method

2. The Client [A]

3. Guiding Conception [B] with Research and Clinical Experience Support [C]

4. Assessment of the Client's Problems, Goals, Strengths, and History [D]

5. Formulation \& Treatment Plan [E]

6. Course of Therapy [F]

7. Therapy Monitoring and Use of Feedback Information [G, H, I]

8. Concluding Evaluation of the Therapy's Process and Outcome [J, K, L]

9. References

10. Tables (optional)

11. Figures (optional) 